\title{
СТВОРЕННЯ ПРОГРАМНОГО ІНСТРУМЕНТУ ДЛЯ ПРОВЕДЕННЯ ДИФЕРЕНЦІЙНОЇ ДІАГНОСТИКИ НЕВРОЛОГІЧНИХ ХВОРОБ МЕТОДОМ ПОТЕНЦІЙНИХ ФУНКЦІЙ
}

\author{
В. 3. Стецюк, А. Й. Савицький, Т. П. Іванова', \\ Г. М. Федушка ${ }^{1}$, А. О. Остапова \\ Національний технічний університет України «Київський політехнічний інститут \\ імені Ігоря Сікорського» \\ ${ }^{1}$ Національна дитяча спеціалізована лікарня «ОХМАТДИТ» \\ В статті розглянуто питання комп'ютеризації медицини та її основні переваги. Описано спосіб допомоги лікарю \\ неврологічного відділення НДСЛ «ОХМАТДИТ» при встановленні діагнозу в умовах відсутності ключового симпто- \\ му. Програмне забезпечення цього комплексу складається з одного блоку, що націлений на диференціювання за- \\ хворювання у нового пацієнта відділення до одного із захворювань групи. Описано методи та інструменти, що були \\ використані при створенні програмного комплексу. Показано приклад роботи програми на тестових даних.
}

Ключові слова: неврологія, інформатизація, диференційна діагностика, симптом, гіпотеза, модель розпізнавання, метод потенціальних функцій, інтерфейс користувача.

\section{СОЗДАНИЕ ПРОГРАММНОГО ИНСТРУМЕНТА ДЛЯ ПРОВЕДЕНИЯ ДИФФЕРЕНЦИАЛЬНОЙ ДИАГНОСТИКИ НЕВРОЛОГИЧЕСКИХ ЗАБОЛЕВАНИЙ МЕТОДОМ ПОТЕНЦИАЛЬНЫХ ФУНКЦИЙ}

\author{
В. 3. Стецюк, А. И. Савицкий, Т. П. Иванова", \\ Г. М. Федушка', А. О. Остапова \\ Национальный технический университет Украины \\ «Киевский политехнический институт имени Игоря Сикорского» \\ ${ }^{1}$ Национальная детская специализированная больница "ОХМАТДЕТ»

\begin{abstract}
В статье рассмотрен вопрос компьютеризации медицины и его основные достоинства. Описан способ помощи врачу неврологического отделения НДСБ «ОХМАТДЕТ» при установлении диагноза в условиях отсутствия ключевого симптома. Программное обеспечение этого комплекса состоит из одного блока, направленного на дифференциацию заболевания у нового пациента отделения к одному из заболеваний группы. Описаны инструменты и методы, использованные при создании программного комплекса. Показан пример работы программы на тестовых данных.
\end{abstract}

Ключевые слова: неврология, информатизация, дифференциальная диагностика, симптом, гипотеза, модель распознавания, метод потенциальных функций, интерфейс пользователя.

() В. З. Стецюк, А. Й. Савицький, Т. П. Іванова, Г. М. Федушка, А. О. Остапова 


\title{
CREATION OF THE PROGRAM FOR NEUROLOGY DECEASES DIFFERENTIAL DIAGNOSTICS BY MEANS OF THE POTENTIAL FUNCTIONS METHOD
}

\author{
V. Z. Stetsyuk, A. J. Savytskyy, T. P. Ivanova ${ }^{1}$, \\ H. M. Fedushka', A. O. Ostapova \\ National Technical University of Ukraine "Igor Sikorsky Kyiv Polytechnic Institute" \\ ${ }^{1}$ National children specialized hospital "OKHMATDYT"
}

\begin{abstract}
Informatization in medicine offers many opportunities to enhance quality of medical support, accuracy of diagnosis and provides usage of accumulated experience. Modern program systems are represented as additional tools to get appropriate advice.

This article offers the way to provide help for neurology department doctor of NCSH "OKHMATDYT" during diagnosis determining. Decision has been made to design the program system for this purpose based on differential diagnostic model.

The key problems in differential diagnosis are symptoms similarity between each other in one disease group and the absence of key symptom. Thus, we need the differential diagnostic model. It is built using the potential function method in characteristics space. Such space of characteristics is formed by 26 points - patients with their symptoms.

The main feature of this method is decision function, building during recognition step united with learning, which became possible with modern powerful computers.
\end{abstract}

Key words: neurology, informatization, differential diagnostics, symptom, hypothesis, recognition model, potential functions method, user interface.

Вступ. Сучасні інформаційні технології все більше впроваджуються в усі сфери життя. Це є актуальним також і для медицини. Комп'ютеризація медичного сектору проявляється як у використанні комп'ютерів для проведення діагностики внутрішніх органів, так і у застосуванні програм для проведення дослідів, аналізу результатів, обробки даних тощо. Це дозволяє проводити обстеження та аналіз швидко, якісно, точно. Також великою перевагою інформатизації медицини є накопичення бази знань: дослідних даних, історій захворювань.

Зараз набувають актуальності системи, які не замінюють людину в процесі роботи, а виконують роль помічника. До такого напрямку можна віднести різні програми, що допомагають встановити той чи інший діагноз, базуючись на такому напрямку в медицині, як диференційна діагностика. Таку програму розглянуто далі у статті.

Застосування такої системи дозволяе за умов відсутності деяких симптомів або схожості з іншими хворобами визначити хворобу пацієнта. Програма пропонує найбільш правдоподібний діагноз на базі накопиченого досвіду. Але в цьому випадку треба пам'ятати одну дуже важливу річ: комп'ютерна програма не замінює людину цілком, вона лише допомагає звузити коло, а саме рішення повинен приймати лікар, базуючись на своїх знаннях та досвіді.

Мета роботи: створення програмного засобу для допомоги лікарю у встановленні діагнозу в умовах схожості з іншими хворобами на основі дослідних даних, що були раніше визначені.

Матеріали та методи дослідження. Для вирішення поставленої задачі, а саме для реалізації помічника-консультанта для лікаря дитячого неврологічного відділення Національної дитячої спеціалізованої лікарні «ОХМАТДИТ» МОЗ України створена пілотна версія програми. Першим етапом був збір дослідних даних для побудови моделі розпізнавання, другим - структурування даних та створення таблиць даних, третім - безпосередньо створення програмної оболонки. Об'єктом дослідження є дитяче неврологічне відділення.

Результати та їх обговорення. В результаті цієї роботи була створена пілотна версія програми-консультанта, яку очікується встановити на персональному комп'ютері лікаря для проведення первинного тестування.

Одна з основних цілей, яка стоїть перед лікарем неврологічного відділення в процесі його роботи, - це вчасне і точне встановлення діагнозу для забезпечення подальшого правильного лікування.

В ході роботи 3 розроблюваною програмою у лікаря повинна бути можливість без додаткових зусиль та навчання вміти користуватись нею. Тому програмну систему було створено з урахуванням цих вимог: інтерфейс програми складається з одного вікна, введення даних реалізовано через імпортування файлу Excel, збереження нових даних здійснюється за допомогою експортування даних 


\begin{tabular}{|c|c|c|c|c|c|c|c|c|c|c|c|c|c|c|c|c|}
\hline 1 & \begin{tabular}{|c} 
Парези на \\
початкуу
\end{tabular} & $\begin{array}{c}\text { ncuxonorivei } \\
\text { posnagan }\end{array}$ & napectesii & Гострий & Поступоекй & 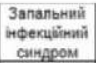 & \begin{tabular}{|l|} 
3e'ssoк s \\
imфexpien
\end{tabular} & $\begin{array}{c}\text { Прамыдний } \\
\text { ситдроми }\end{array}$ & $\begin{array}{c}\text { Haростання } \\
\text { cna6кості } \\
\text { M'яsie }\end{array}$ & $\begin{array}{c}\text { 3нискения } \\
\text { napesy }\end{array}$ & $\begin{array}{c}\text { ATakcia } \\
\text { Mosouroosa }\end{array}$ & $\begin{array}{c}\begin{array}{c}\text { ATakcia } \\
\text { eecrubynap } \\
\text { Ha }\end{array} \\
\end{array}$ & $\begin{array}{c}\text { Aтаксі⿱ } \\
\text { сенститиена }\end{array}$ & $\begin{array}{c}\text { A Arakcia } \\
\text { noбna }\end{array}$ & Пріsaице & ЗахворюваннА \\
\hline$=0$ & 1 & -1 & 1 & -1 & 1 & -1 & -1 & 1 & -1 & 1 & -1 & -1 & -1 & -1 & \begin{tabular}{|l|} 
Прізsеище 1 \\
\end{tabular} & Poscianuй склеро \\
\hline$=6$ & -1 & -1 & -1 & 1 & 1 & -1 & -1 & -1 & -1 & 1 & 1 & -1 & -1 & -1 & Прівеичер 2 & Poscianui cкnepos \\
\hline 45 & -1 & -1 & 1 & -1 & 1 & -1 & 1 & -1 & -1 & 1 & -1 & -1 & 1 & -1 & прізеице 3 & Розсіяний склерол \\
\hline 50 & -1 & -1 & 1 & -1 & -1 & -1 & 1 & 1 & -1 & $i$ & 1 & -1 & -1 & -1 & пррisenще 4 & Poscianiuи склероs \\
\hline$=0$ & -1 & -1 & 1 & -1 & 1 & -1 & -1 & -1 & -1 & 1 & -1 & 1 & -1 & -1 & Прізвище 5 & Розсіаний скnероз \\
\hline$>0$ & -1 & -1 & 1 & -1 & 1 & -1 & -1 & 1 & -1 & -1 & -1 & -1 & -1 & -1 & Прімвище 6 & Розсіяний склероs \\
\hline$=0$ & -1 & -1 & 1 & -1 & 1 & -1 & -1 & 1 & -1 & -1 & 1 & -1 & -1 & -1 & Пріsenue 7 & Poscianий cknepos \\
\hline 50 & -1 & -1 & 1 & -1 & 1 & -1 & -1 & (1) & -1 & -1 & -1 & -1 & -1 & -1 & Прізвище 8 & Розсіаний склерол \\
\hline $10 \%$ & -1 & -1 & 1 & -1 & 1 & -1 & -1 & 1 & -1 & 1 & -1 & -1 & -1 & -1 & прiosume 9 & Poscianuй стnероs \\
\hline 11 & -1 & -1 & -1 & -1 & 1 & -1 & -1 & 1 & -1 & -1 & 1 & -1 & -1 & -1 & Пріseище 10 & $\begin{array}{l}\text { Гострий ровсіяний } \\
\text { eнцефапоміеліт }\end{array}$ \\
\hline 1 & 1 & -1 & -1 & 1 & -1 & -1 & -1 & 1 & -1 & -1 & 1 & -1 & -1 & -1 & Пріввище 11 & \begin{tabular}{|l} 
Гостриий розсіяний \\
енцефаломіеліт
\end{tabular} \\
\hline 1 & -1 & -1 & -1 & -1 & 1 & 1 & 1 & -1 & -1 & 1 & -1 & -1 & -1 & -1 & Пріseище 12 & 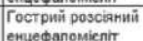 \\
\hline 241 & -1 & -1 & 1 & 1 & -1 & -1 & 1 & 1 & -1 & 1 & 1 & $\left.\right|^{-1}$ & -1 & -1 & npisenщu 13 & $\begin{array}{l}\text { Гострий розсіаний } \\
\text { енцефаломiеліт }\end{array}$ \\
\hline ss 1 & -1 & -1 & -1 & 1 & -1 & 1 & -1 & -1 & -1 & -1 & -1 & -1 & 1 & -1 & חpisenuse 14 & 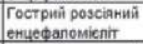 \\
\hline 16 & -1 & -1 & 1 & -1 & 1 & -1 & -1 & 1 & -1 & -1 & 1 & -1 & -1 & -1 & nрівеище 15 & $\begin{array}{l}\text { Гострий розсіяний } \\
\text { енцефаломіеліт }\end{array}$ \\
\hline 17 & 1 & -1 & 1 & 1 & -1 & -1 & -1 & -1 & -1 & 1 & -1 & -1 & -1 & -1 & Пріsвище 16 & $\begin{array}{l}\text { Гострий розсіаний } \\
\text { енцефапоміеліт }\end{array}$ \\
\hline
\end{tabular}

Рис. 1. Фрагмент таблиці вхідних даних для діагностики групи неврологічних захворювань

в файл Excel, впроваджено можливість друку результатів дослідження у форматі Word.

Розроблена система призначена для проведення розпізнавання невідомої хвороби та визначення попереднього діагнозу що допоможе лікарю прийняти правильне рішення, базуючись на своїх знаннях та досвіді. В системі створена можливість для проведення діагностики за допомогою кількох алгоритмів розпізнавання: методу потенціальних функцій, методу відстаней та методу частот.

Для створення програми використовували моделюючу вибірку із 26 пацієнтів (в програмному алгоритмі один пацієнт із набором симптомів являється точкою в просторі ознак).

Методи вирішення задачі. В основі роботи програмного комплексу лежить побудова моделі диференційної діагностики на основі дослідних даних. Модель діагностики будується в даному випадку на основі досліджених даних вже продиференційованих (відомих) захворювань. Дані подаються у вигляді таблиці, що зберігається в файлі Excel (фрагмент таблиці - рис. 1).

Кожний рядок таблиці описує логічний вектор для одного з об'єктів - пацієнта із набором ознак (симптомів). У статті наведено лише фрагмент таблиці, оскільки весь обсяг вхідних даних (симптомів) є великим і може спричинити зниження читабельності. У таблиці присутня колонка із назвою захворювання (останній стовпець), яка не бере участі у процесі розпізнавання: вона була додана для зручності користування базою пацієнтів так само, як і колонка «Прізвище». Замість цього, як можна побачити з рисунку, в першій колонці таблиці розміщено кодування для групи захворювань, що відповідає гіпотезі. Відповідними значеннями гіпотези є:
0 якщо справедлива перша гіпотеза (розсіяний склероз);

1 якщо справедлива друга гіпотеза (гострий розсіяний енцефаломієліт);

2 якщо справедлива третя гіпотеза (лейкоенцефаліт).

Для процесу навчання таблиця в файлі Excel складається із значень ознаки:

1 якщо симптом присутній;

-1 якщо симптом відсутній;

0 що симптом невідомий.

Після завантаження файлу Excel у вікні програми формується таблиця, за допомогою якої відбувається процес діагностики та подальша робота 3 програмою. Ці дані таблиці формують вирішальну функцію, за допомогою якої здійснюється диференціювання хвороби до одного з трьох захворювань класу. Побудова моделі здійснюється, в свою чергу, за допомогою одного з методів розпізнавання образів - наприклад, метода потенціальних функцій.

Другою групою вхідних даних є набір ознак захворювання, яке потрібно диференціювати (невідома хвороба). Ознаки подаються у вигляді таблиці 3 одним рядком в файлі Excel так само, як і в попередньому випадку; під час імпортування файлу створюється таблиця, яка бере участь у процесі диференціювання.

Для прикладу розглянемо такий набір симптомів (табл. 1).

Після проведення процесу розпізнавання був встановлений попередній діагноз: гострий розсіяний енцефаломієліт (рис. 2).

Після завершення процесу диференціювання лікар-користувач має можливість зберегти нові 


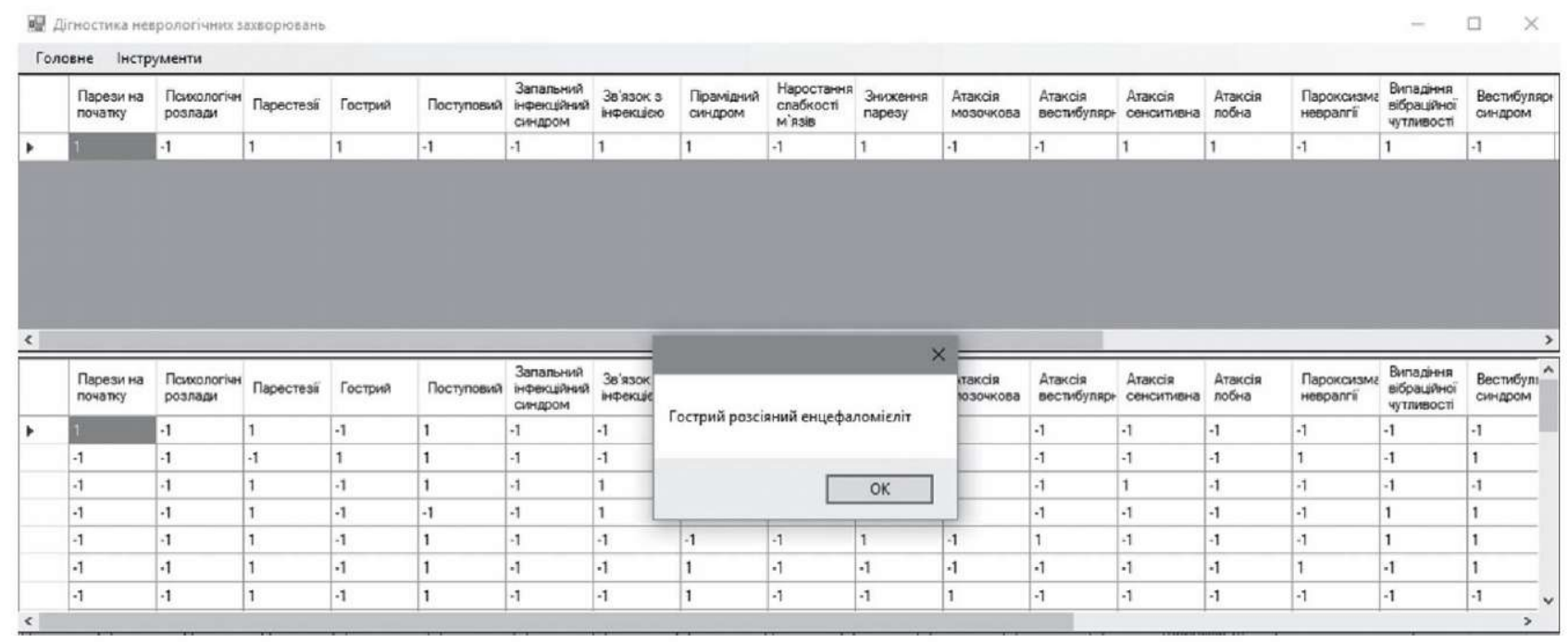

Рис. 2. Знімок програмного вікна з результатом розпізнавання

Таблиия 1

Набір ознак для проведення розпізнавання

\begin{tabular}{|l|c|}
\hline Парези на початку & 1 \\
\hline Психологічні розлади & -1 \\
\hline Парестезії & 1 \\
\hline Гострий & 1 \\
\hline Поступовий & -1 \\
\hline Запальний інфекційний синдром & -1 \\
\hline Зв'язок з інфекцією & 1 \\
\hline Пірамідний синдром & 1 \\
\hline Наростання слабкості м'язів & -1 \\
\hline Зниження парезу & 1 \\
\hline Атаксія мозочкова & -1 \\
\hline Атаксія вестибулярна & -1 \\
\hline Атаксія сенситивна & 1 \\
\hline Атаксія лобна & 1 \\
\hline Пароксизмальні невралігї & -1 \\
\hline Випадіння вібраційної чутливості & 1 \\
\hline Вестибулярний синдром & -1 \\
\hline Дизартрія & -1 \\
\hline Симптом Седана & -1 \\
\hline Ністагм & 1 \\
\hline Ретробульбарний неврит & -1 \\
\hline Зниження зору & ж** \\
\hline Прізвище & \\
\hline
\end{tabular}

дані у базі даних для подальшої участі у процесах диференціювання та роздрукувати звіт із результатами розпізнавання.

Програмний комплекс було спроектовано і розроблено у програмному середовищі Microsoft Visual Studio. В програмі також реалізована можливість створення простого звіту у форматі Microsoft Word.

Висновки. Отже, проаналізувавши функції даної системи, можна сказати, що використання такої програми значно полегшить роботу лікаря неврологічного відділення та надасть великі переваги, серед яких особливо необхідно виділити можливість встановлення попереднього діагнозу, накопичення даних щодо хвороб та використання їх у подальших процесах диференціювання, створення простих звітів.

\section{Література.}

1. Хэгглин Р. Дифференциальная диагностика внутренних болезней / Р. Хэгглин ; пер. с нем. Н. П. Вельмина, Э. Р. Левицкого, Т. И. Меерзон, В. С. Мойсеева. - М.: Триада-Х, 1997. - 794 с.

2. Васильев В. И. Распознающие системы : справочник / В. И. Васильев. - Киев : Наукова думка, 1969. - 292 с. 3. Славин М. Б. Методы системного анализа в медицинских исследованиях / М. Б. Славин. - М. : Медицина, 1989. - 304 с.

4. Шилдт Г. С\# 4.0: полное руководство / Г. Шилдт; пер. с англ. - М. : ИД Вильяме, 2011. - 1056 с.

5. Троелсен Э. Язык программирования С\# 2008 и платформа .NET 3.5 / Э. Троелсен ; пер. с англ. - М.: И. Д. Вильяме, 2011. - (4-е изд.) - 1344 с.

6. Нойес Б. Привязка данных в Windows Forms / Б. Нойес; пер. с англ. - М. : Бином-Пресс, 2009. - 632 с. 


\section{References.}

1. Hegglin, R. (1997). Diferentsial'naya diagnostika vnutrennikh boleznei [Differential diagnosis of internal diseases]. Moscow:Triada-X [in Russian].

2. Vasil'ev, V. I. (1969). Raspoznayushchie sistemy : spravochnik [Recognition systems : a handbook]. Kyiv: Naukova dumka [in Russian].

3. Slavin, M. B. (1989). Metody sistemnogo analiza v meditsinskikh issledovaniyakh [System analysis methods in medical research]. Moscow: Meditsina [in Russian].
4. Shildt, H. (2011). C\# 4.0 :polnoe rukovodstvo [C\# 4.0 : The Complete Reference]. Moscow: Vil'yams Publ. [in Russian].

5. Troelsen, A. (2011). Yazyk programmirovaniya C\# 2008 i platforma .NET 3.5 [Pro C\# 2008 and the .NET 3.5 Platform]. Moscow: Vil'yams Publ. [in Russian].

6. Noys, B. (2009). Privyazka dannykh v Windows Forms [Data Binding with Windows Forms]. Moscow: BinomPress. [in Russian]. 